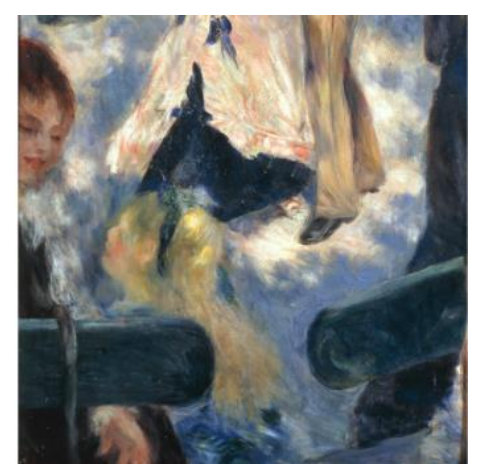

\title{
Museu de Favela e biografias urbanas ${ }^{1}$
}

Favela museum and urban biographies

\author{
Greciely Cristina da Costa ${ }^{2}$ \\ ORCID: https://orcid.org/0000-0001-9738-8985
}

\begin{abstract}
Resumo: A partir do domínio Saber Urbano e Linguagem e da compreensão de museu como instituição que atua nos processos de individuação do sujeito, se configurando também como prática de significação (ORLANDI, 2013a), tecemos algumas considerações sobre o conceito de museu de território. Num gesto de apropriação teórica, refletimos discursivamente sobre este conceito para observar as especificidades do Museu de Favela como uma das formas do discurso urbano. Como resultado, desenvolvemos a noção de biografia urbana e analisamos seu funcionamento no processo discursivo que chamamos biografização.
\end{abstract}

Palavras-chave: Saber urbano e linguagem; Museu de território; Discurso; Biografia urbana

Abstract: Based on the domain of Urban Knowledge and Language and on the understanding of the museum as an institution that operates in the processes of individuation of the subject, also configuring itself as a practice of meaning (ORLANDI, 2013a), we deal with the concept of territory museum. In a gesture of theoretical appropriation, we reflect discursively on this concept to observe the specificities of the Favela Museum as a form of urban discourse. As a result, we developed the notion of urban biography and analyzed its functioning in the discursive process that we call biographization.

Keywords: Urban knowledge and language; Territory museum; Discourse; Urban biography.

\footnotetext{
${ }^{1}$ Além de fazer parte dos resultados do Projeto "Vozes e formas do texto expográfico: cruzamento de encontros e leituras", este trabalho está associado ao Projeto de Pesquisa "Imagens da Cidade: Discurso e Produção do Conhecimento" financiado pela FAPESP - Processo: 18/26073-8.

2 Pesquisadora do Laboratório de Estudos Urbanos da Universidade Estadual de Campinas LABEURB/UNICAMP. E-mail: greciely@ unicamp.br
} 
No território urbano, o corpo dos sujeitos e o corpo da cidade formam um, estando o corpo do sujeito atado ao corpo da cidade, de tal modo que o destino de um não se separa do destino do outro. Em suas inúmeras e variadas dimensões: material, cultural, econômica, histórica etc. O corpo social e o corpo urbano formam um só.

Eni Puccinelli Orlandi (2004, p. 11).

Em 2008, foi fundado o Museu de Favela (MUF), na cidade do Rio de Janeiro, com base no conceito de museu de território. Um museu cuja extensão é o próprio território que recobre e dele fazem parte os sujeitos que o habitam. Nesse caso, o Museu da Favela abrange os morros Cantagalo, Pavão e Pavãozinho, localizados na zona sul da cidade, entre os bairros Ipanema, Copacabana e Lagoa, com cerca de 20 mil moradores.

Neste trabalho, inscrito no domínio do Saber Urbano e Linguagem, tecemos algumas considerações sobre o conceito de museu de território e nos apropriamos dele discursivamente para refletir sobre a constituição do Museu de Favela e os deslocamentos de sentido produzidos pelo modo de organização de seu acervo, exposições e visitações dadas as especificidades na instalação e regulação das "coisas-a-saber" (PÊCHEUX, 1997) sobre o sujeito e sobre o espaço urbano.

Ou seja, interrogamos o processo produção de arquivos considerando o museu como instituição que atua nos processos de individuação do sujeito e como prática de significação (ORLANDI, 2013a).

Tomamos teoricamente território e/ou favela pela noção de espaço urbano, enquanto um espaço “material (político-simbólico), sócio-histórico, com uma quantidade de sujeitos (significantes) vivendo dentro" (ORLANDI, 2001b, p. 202). Um espaço urbano específico da cidade, no qual se pode observar, pela linguagem, o funcionamento do social, das relações sociais. Assim, nos referimos ao espaço urbano para falar do lugar teórico dado ao território em nossa reflexão.

Neste percurso, nos norteamos pelas seguintes inquietações: quais são as particularidades de um museu de território? Como elas comparecem no Museu de Favela? Como se dá a instauração da memória de arquivo do MUF? De que modo é possível observar a relação do sujeito com o espaço urbano neste arquivo?

Essas mesmas perguntas nos levaram a observar o que nomeamos biografia urbana, caracterizada por ser um lugar de significação no qual sujeito e espaço urbano se entrelaçam num só corpo. Em deriva, analisamos o processo discursivo de biografização que se instala e estrutura o Museu de Favela.

Para isso, começamos pela leitura do conceito de museu de território. 


\section{Museu de território ${ }^{3}$}

O conceito de museu de território - bem como os de museu comunitário, museu a céu aberto, museu local - é elaborado no âmbito da "nova museologia" ou da ecomuseologia definida por Varine (2003) como uma alternativa à museologia tradicional. $\mathrm{O}$ autor explica que se alinham à ecomuseologia todos os museus que consideram um território como um todo em vez de se atribuir a museu a existência de um edifício; que tenham origem na população deste território; que se estabeleçam sobre o patrimônio desta comunidade no território em vez de construir ou gerir uma coleção; e que estejam a serviço da sociedade, visando o seu desenvolvimento global e sustentável.

O museu de território se define, portanto, dentro do quadro dos ecomuseus, em decorrência desses deslocamentos, em vez do prédio institucional, ele abarca um território, o patrimônio ocupa o lugar da coleção e a atenção está naqueles que habitam um território em oposição ao preponderante enfoque dado aos visitantes como acontece nos museus tradicionais.

De antemão, podemos dizer que o conceito de museu de território além de abrigar um processo sócio-histórico de dupla musealização, pois tanto o território quanto os seus habitantes são musealizados, ele revolve a própria concepção de objeto de museu.

Brulon (2015) assinala que a invenção do ecomuseu remonta aos anos 1970-1980, em uma conjuntura marcada pela contracultura e o anseio pela emancipação da cultura popular na Europa. Sua invenção assim se insere num movimento político que busca encontrar um "antídoto à mundialização das culturas e alienação dos patrimônios" (VARINE, 2003, p. 3).

O ecomuseu "representou a utopia da democratização da memória" (BRULON, 2015, p. 267), pois seu projeto consiste em dar lugar à cultura silenciada, à cultura posta à margem da musealização em detrimento da cultura erudita das elites, da preservação dos registros de memória e visão de mundo das classes mais privilegiadas assim como do modelo de museu tradicional, fechado, organizado em torno de suas próprias coleções, de suas obras de arte.

Para Chagas (2011) trata-se de um processo amplo de democratização que não se limita a democratizar o acesso aos museus, mas significa a própria democratização do

\footnotetext{
${ }^{3}$ São vários os autores que se dedicam ao estudo da ecomuseologia, produzindo diferentes abordagens e densas discussões acerca das problemáticas em torno dos princípios e tipos de museus que se enquadram nesta perspectiva. Neste trabalho, não buscamos nos debruçar sobre elas, trazemos apenas alguns de seus pontos sem adentrar em sua complexidade.
} 
museu como uma das formas de democratizar a democracia, tendo em vista que o museu se ressignifica como tecnologia, um dispositivo para os movimentos sociais já que os ecomuseus surgem para acolher a memória dos mais diversos grupos sociais. No Brasil, a

diversidade museal trouxe a erosão das tipologias museológicas baseadas em disciplinas e acervos, o alargamento do espectro de vozes institucionais, a flexibilização das narrativas museográficas de grandes sínteses nacionais ou regionais, a experimentação de novos modelos museológicos e museográficos, a disseminação de museus e casas de memória por todo o país (CHAGAS, 2011, p. 12) .

O Museu de Favela, como veremos a seguir, pode ser considerado um exemplo desta diversidade.

Embora haja diferenças entre o museu tradicional e o ecomuseu, Scheiner (2012) tem críticas à institucionalização e ao desenvolvimento prático do projeto deste último ${ }^{5}$. Por um lado, a autora assevera que o ecomuseu "não é, certamente, uma ruptura com o museu tradicional, nem a única forma de relacionar, de forma ativa, museus e sociedade". Por outro lado, afirma que, "sem dúvida, constitui uma alternativa interessante para a ressignificação de comunidades que desejam valorizar e dinamizar suas relações com o espaço, o tempo e o patrimônio, em âmbito local", mas pondera que isso se efetiva "desde que não seja percebido como ferramenta (como quase sempre acontece)", porque, para ela, "ferramentas são instrumentos que levam facilmente à manipulação" (SCHEINER, 2012, p. 24-25).

\footnotetext{
${ }^{4}$ Chagas cita como exemplos: Koahi - Museu dos Povos Indígenas do Oiapoque (Oiapoque, AP), Museu Casa de Chico Mendes (Xapuri, AC), Museu da Maré (Rio de Janeiro, RJ), Casa de Memória Daniel Pereira de Mattos do Centro Espírita e Culto de Oração Casa de Jesus Fonte de Luz (Rio Branco, AC), Museu Indígena de Coroa Vermelha (Santa Cruz de Cabrália, BA), Museu Magüta dos índios Ticuna (Benjamim Constant, AM), Ecomuseu da Amazônia (Belém, PA), Museu Vivo de Duque de Caxias (Duque de Caxias, $\mathrm{RJ})$.

${ }^{5}$ Não debateremos, neste trabalho, as questões criticadas por Scheiner, mas é importante fazer referência a elas dada sua relevância. Referindo-se, criticamente, à institucionalização dos ecomuseus, Sheiner ressalta que a longo prazo muitas vezes os ecomuseus vão se assemelhando aos museus tradicionais, na medida em que: "a) se institucionalizam, parecendo-se cada vez mais com os museus tradicionais - caso em que as lideranças assumem, em nome do grupo, seu papel norteador da ação (seja por delegação natural, por sedução ou por imposição) [...]; b) se compartimentam, fazendo um discurso destoante da ação - o discurso fala de escolhas do grupo, a ação mostra claramente que apenas alguns decidem; o discurso fala dos processos culturais, a ação museológica se exerce prioritariamente sobre os produtos (objetos, cenários); c) se autoconsomem [...] esgotando suas propostas em um incessante fluxo de debates, votações e assembleias, que paralisam, no todo ou em parte, a ação [...]; d) se extinguem - seja por dissolução, quando optam por finalizar a experiência, por 'desmusealizar-se' [...], seja por transformação, quando se tornam definitivamente museus tradicionais a céu aberto (aqui, exerce um papel importante a influência de lideranças externas ao grupo)" (SCHEINER, 2012, p. 26).
} 
A nosso ver, qualquer museu, enquanto instituição, conjuga em seu bojo confrontos de ordem política em que pesam as relações de força, porque não é sem disputa que se circunscreve um patrimônio. Além disso, há o "jogo do esquecimento na memória" (ORLANDI, 2013a) que se presentifica nas práticas de significação. Com efeito, é preciso realçar que a institucionalização do museu de território acontece já afetado por esse jogo.

Atentamo-nos para o fato de que a invenção do ecomuseu incide, sobretudo, no objeto de musealização, pois se na museologia tradicional o objeto corresponde às coleções e seu valor documental, na ecomuseologia se privilegiam as experiências humanas ao lado dos gestos de interpretações possíveis acerca dos objetos. Altera-se, portanto, a relação sujeito-objeto.

Segundo Brulon (2015b, p. 31), passa haver um "novo sentido conferido ao objeto artístico pela arte contemporânea atuando na reordenação dos enunciados sobre os objetos e os valores neles investidos, sobretudo nos museus não introduzidos à linguagem artística clássica" e, com o surgimento dos ecomuseus, as relações do humano com o seu meio passam a ser o foco da musealização. Assim, as categorias classificatórias e todo o trabalho de curadoria, ordenação, coleta, indexação, pesquisa e exposição dos objetos e da própria compreensão de objeto são perturbados, pois a noção e/ou estatuto de obra de museu são desestabilizados à medida que entram cena as relações sociais estabelecidas em um território.

Essa questão da ressignificação do museu, sobretudo no tocante ao seu objeto é um dos pontos que nos interessa analisar a partir do modo como se configura aí uma outra relação de sentido com o objeto. Além disso, aponta para um lugar de inscrição do sujeito, haja vista que ao comparar a ecomuseologia e o museu tradicional, Varine (2003) mostra que a principal diferença entre eles recai sobre os habitantes do território, pois eles passam a ser entendidos como autores-atores do ecomuseu.

Varine (2003) ressalta que, enquanto alternativa ao museu tradicional, o ecomuseu não é uma instituição finita, mas torna-se um processo inserido na duração das dinâmicas de seu próprio desenvolvimento. Esse processo é feito de autores-atores: a comunidade e seus membros em primeiro plano, aliados a profissionais, técnicos, pesquisadores, grupos e entidades que participam da vida social do território e a representam.

Pela via da Análise de Discurso, teoria que fundamenta a área de pesquisa Saber Urbano e Linguagem, traçaremos a seguir um outro percurso de reflexão em vista do conceito de ecomuseu, ou melhor, de museu de território. Lidamos com a questão do 
objeto de museu e de museu como objeto considerando-a uma questão que toca os processos de significação. Da mesma maneira, nos dedicamos a analisar o lugar de inscrição do sujeito. No entanto, não tratamos do par autores-atores. Em vez disso, propomos a noção de biografia urbana, que de certo modo pode fazer ressoar esse par, para sondar as especificidades em torno do lugar de inscrição do sujeito que não se constitui sem ligação com o espaço urbano no Museu de Favela. Assim, a relação sujeitoespaço reside num processo discursivo que vamos chamar de biografização, no qual se entrelaçam simbolicamente espaço urbano e sujeito num só corpo.

\section{O Museu de Favela como uma forma de discurso urbano}

Do ponto de vista do dispositivo teórico-analítico da Análise de Discurso, a prática científica instaurada no domínio do Saber Urbano e Linguagem em seu modo de reflexão se configura e se especifica "na convergência de dois processos de significação: o da espacialização da linguagem na cidade e o da simbolização do espaço urbano" (ORLANDI, 2001, p. 7). Nesta articulação entre linguagem e espaço urbano, a cidade assim é observada por meio da linguagem e a linguagem é concebida como um observatório dos fenômenos urbanos (ORLANDI, 2004).

O trabalho deste domínio é então voltado para a compreensão da cidade em suas formas de se significar e, por conseguinte, produzir sentidos, levando-se em conta que, enquanto espaço simbólico-político-ideológico, a cidade demanda gestos de interpretação ao mesmo tempo em que coloca questões sobre a constituição e os processos de individuação do sujeito citadino bem como sobre a vida em sociedade.

É, pois, no traçado desta convergência que observamos algumas especificidades do funcionamento discursivo do Museu de Favela.

Para isso, investimos no gesto de apropriação uma vez que embora façamos remissão a estudos de campos científicos tais como o da museologia, não mantemos com eles uma relação de reprodução de saberes. Nosso gesto de apropriação consiste na inscrição desses saberes em nosso quadro teórico. Nas palavras de Pêcheux (1990), a apropriação de um objeto de ciência implica em uma mudança de terreno. Essa mudança de terreno por sua vez é operada por uma prática teórica, ou seja, "por meio de um trabalho conceitual determinado" (PÊCHEUX, 2011, p. 25).

Sendo assim, nesta seção, procuramos dar consequência a uma compreensão discursiva de museu de território bem como propor a noção de biografia urbana a fim de 
analisarmos o processo discursivo de biografização que se presentifica no MUF. Por sua vez, essa proposição já é um dos efeitos do trabalho de análise.

\subsection{O museu como objeto ideológico}

Compreendemos o museu como "espaço material (simbólico, político, histórico e físico)" (PFEIFFER, 2013, p. 226), como instituição que regula a gestão da memória de uma sociedade em meio a relações de força e poder. E, com isso, não só administra as múltiplas coisas-a-saber, isto é, "conhecimentos a gerir e a transmitir socialmente" (PÊCHEUX, 1997, p. 34) como também, para isso, intervém na produção de arquivos.

Enquanto museu, o Museu de Favela não escapa dessas determinações. Levandoas em conta e, em face de sua especificidade como museu de território, (re)situamos o Museu de Favela como uma das formas do discurso urbano assim como a pichação, inscrições, painéis, rap, rodas de conversa, poesia urbana, grafitos, entre outros. Isso porque a cidade tem um corpo significativo com suas formas de significar e o museu de território reúne em seu espaço sujeitos e significantes engendrando uma narratividade ${ }^{6}$ urbana, isto é, um "modo de se trabalhar a espessura semântica da cidade, atravessar o urbano saturado e flagrar o real da cidade se significando" (ORLANDI, 2004, p. 36).

A narratividade urbana se constitui por um conjunto de espaços narrativos. Para nós, a biografia faz parte desse conjunto. A biografia é uma das vias da narratividade urbana posta em circulação no MUF, e estabelece uma relação estruturante com o museu e seu objeto.

O museu de território ao mesmo tempo que instala se estrutura em biografias, pois tem em sua fundação um princípio biográfico: descrever, contar, narrar, mostrar o território e seus habitantes. Esse princípio se configura discursivamente como um processo de significação que instaura um modo de significar a favela e seus moradores enlaçados.

Ao lado disso, o objeto do museu de território não é uma obra de arte, um espécime científico, obras raras, entre outros, comumente expostos nos museus tradicionais. O objeto do museu é o próprio museu em sua história e existência. Em suas condições de vida. Ou ainda, o objeto do museu de território é tecido de espaços e sujeitos em suas

\footnotetext{
${ }^{6}$ Fazemos referência a dois modos de pensar a narratividade teorizados por Orlandi em momentos diferentes: à narratividade urbana remetendo-a às formas de significar incluídas na própria forma material da cidade e à narratividade, cujo núcleo de definição é o funcionamento do interdiscurso.
} 
condições materiais de existência. Com efeito, altera-se indissocialmente, portanto, o estatuto de museu e de objeto de museu.

Neste caso, não se trata de objeto empírico. O museu de território se constitui como objeto ideológico. De acordo com Pêcheux (2011), um objeto ideológico apenas existe "como relações de forças historicamente móveis, como movimentos flexíveis que são surpreendentes por causa do paradoxo que eles possuem. Esses movimentos funcionam como unidades divididas" (p. 97), cuja propriedade consiste em ser, igualmente, idêntico e antagônico entre si.

Assim, propomos mirá-lo não sob efeito de univocidade lógica como objeto físico, lógico ou formal, mas compreendê-lo como objeto ideológico constituído de relações de forças que operam na construção das evidências subjetivas do sentido e do sujeito. Com isso, propomos compreendê-lo, também, como objeto simbólico, ou seja, como objeto instituído de gestos de interpretação e que produz significação.

Nesta via de reflexão, o espaço urbano e os sujeitos constituem o Museu de Favela de uma maneira singular, instituem biografias urbanas, pois eles encontram-se atrelados no processo discursivo de biografização. Por esse processo, é possível observar o funcionamento de um discurso, no qual "estando o corpo do sujeito atado ao corpo da cidade [...] o destino de um não se separa do destino do outro. Em suas inúmeras e variadas dimensões: material, cultural, econômica, histórica etc.” (ORLANDI, 2004, p. 11).

Dada essa especificidade, enquanto um processo discursivo, a produção de biografias espacializa sentidos no corpo urbano ao mesmo tempo em que nelas se inscrevem sujeitos, discursividades. Configura um corpo de metaforizações.

Orlandi (2017) situa o relato, o conto, a lenda ou o causo como matéria. "Matéria de memória em funcionamento em seus trajetos e deslocamentos" (p. 32) que funciona pela narratividade. Fazendo a distinção entre narrativa e narratividade, Orlandi (2013b) propõe pensar a narratividade, neste caso, como sendo "a maneira pela qual uma memória se diz em processos identitários, apoiados em modos de individuação do sujeito, afirmando/vinculando seu pertencimento a espaços de interpretação determinados, consoantes a específicas práticas discursivas" (ORLANDI, 2013b, p. 28).

A biografia urbana também é matéria de memória em movimento. É lugar de incidência do interdiscurso, aquilo que fala antes, em outro lugar e independentemente, “corpo de traços (sócio-históricos) que formam memória” (PÊCHEUX, 2011, p. 147). 


\subsection{Biografias urbanas}

Em linhas gerais, biografia pode ser tomada como sinônimo de descrição de vida, história de vida, memória de vida, narrativa de vida, recordação de vida, relato de vida. A biografia é uma forma de contar a vida de alguém, este é seu objeto.

No universo literário, biografia é um termo associado a obras literárias que retratam a vida de uma pessoa, esta na maioria das vezes é reconhecida socialmente: um artista, político, cientista, atleta etc. Mas há também biografias de pessoas comuns que, por alguma razão, são de interesse público, social.

Autor e protagonista são elementos estruturantes da biografia neste universo. Muitas vezes eles são um só.

"Em seu sentido lato, de escrito que tem por objeto a história de uma vida particular, a biografia está ligada ao próprio surgimento da história como forma de conhecimento do mundo" (SCHMIDT, 2003, p. 58). Nesta vertente, a biografia ocupa um lugar de observação que passa pelos regimes de historicidade manejados na sociedade ao longo do tempo.

No campo da historiografia, encontram-se biografias dos "grandes homens" da história. Todavia, Schmidt (2003) ratifica que, por exemplo, no Brasil, há um movimento de produção de biografias de militantes operários, escravos e ex-escravos. Uma brecha que acolhe biografias à margem e vem sendo esgarçada.

Uma biografia pressupõe expor a história de vida de alguém. Por isso, sem dúvida, a biografia é terreno da linguagem, da história e do sujeito. Um modo de produção de sentidos, uma forma material de discurso.

Em sua estrutura se entrelaçam a ordem de um dizer de si para o outro ou um falar sobre o outro para outro(s). Pressupõe uma relação de interlocução e, portanto, a produção de efeitos de sentido. Põe em movimento um funcionamento discursivo intrinsecamente ligado à memória discursiva. Trata-se de um acontecimento do dizer em curso, pois a partir da biografia, os sujeitos tornam-se os próprios personagens de sua vida e dão a ela uma história. Como preconiza Delory-Momberger (2012), é o lugar no qual a existência humana ganha forma.

A adjetivação "urbana" para biografia decorre da singularidade da associação entre sujeito e espaço urbano. A biografia urbana resulta da observação de que no Museu de Favela, a vida do sujeito não se separa da vida da favela assim como a vida da favela não se separa da vida do sujeito. Eles são significados em sua coexistência, na 
singularidade de seu laço, produzindo um efeito de metonimização ${ }^{7}$ concernido no percurso de sentidos entre um e o outro.

Portanto, discursivamente pensamos a biografia urbana como um processo discursivo de produção de sentidos e sujeitos. Um processo que visibiliza a relação mediada pela linguagem-e-ideologia entre sujeitos e suas condições reais/materiais de existência. Ou, ainda, forja ao mesmo tempo que flagra o modo como cada sujeito se relaciona com as suas condições de existência, com o espaço urbano do qual também é corpo.

Frisando que o discurso, "enquanto teoria geral da produção dos efeitos de sentido" (PÊCHEUX, 2019 [1969], p. 146), tem espessura material, densidade políticoideológica, camadas de significação, colocamos então, em análise, este processo de biografização como lugar de observação da produção dos efeitos de sentido no Museu de Favela.

\section{Traços de um discurso institucional museológico}

Como procedimento e método, a Análise de Discurso pratica a "relação entre a análise como descrição e a análise como interpretação" (PÊCHEUX, 1997, p. 17, grifos do autor), em um contínuo vai-e-vem. Teoria e análise se conjugam neste movimento. E dando início à análise, partimos da descrição do Museu de Favela, realçando condições de produção de significação, no qual está inserido, e cotejando a relação inseparável entre linguagem e exterioridade.

Como dissemos anteriormente, o Museu de Favela foi fundado em 2008, na cidade do Rio de Janeiro. Institucionalmente, o MUF é apresentado como uma organização não governamental privada de caráter comunitário fundado por moradores - reconhecidos como lideranças culturais, engajados em atividades e projetos artísticos-culturais - das favelas Pavão, Pavãozinho e Cantagalo do Rio de Janeiro.

Sua estrutura administrativa e de gestão sustenta-se em um modelo de governança em torno do patrimônio, redes e projetos culturais. O MUF recebe doações, conta com o trabalho de voluntários e apoio de parceiros como o Instituto Brasileiro de Museus (IBRAM), governo federal, governo do Estado do Rio de Janeiro, Universidade Federal

\footnotetext{
${ }^{7}$ Refletimos sobre a metonimização no texto "Discurso, Cidade e História: metonimização entre favela e favelado e seus efeitos", publicado em 2013 no livro "Cidades em movimento".

${ }^{8}$ Para proceder à análise, exploramos traços de um discurso institucional produzido pela discursividade do website do MUF: https://www.museudefavela.org/. Último acesso em 20 de junho de 2020.
} 
do Rio de Janeiro, Puc-Rio, Unirio, Rede de Museologia Social, entre outros. Realiza oficinas, projetos culturais, exposições e recebe visitações, além de oferecer dois diferentes circuitos de visitação pelo seu território.

Por esses traços de um discurso institucional, notam-se aí as bases às quais se refere Varine (2003), que caracterizam um museu de território, tendo em sua gênese a comunidade e seus membros, contando com o envolvimento de profissionais, pesquisadores, grupos e entidades na realização de seu projeto.

Em relação à significação do MUF como museu e sobre a questão do objeto do museu, da primeira página de seu website, trazemos o seguinte recorte (R1):

R1: Nesse primeiro museu territorial e vivo sobre memórias e patrimônio cultural de favela do mundo, o acervo são cerca de 20 mil moradores e seus modos de vida, narrativos de parte importante e desconhecida da própria história da Cidade do Rio de Janeiro.

Por esta descrição, é possível observar o modo pelo qual o MUF vai sendo caracterizado como um museu territorial e vivo, dois adjetivos que fazem vir à tona, pelo não-dito na relação com o já-dito, uma contraposição com aquilo que poderia remeter, interdiscursivamente, ao museu tradicional, a objeto inanimado. Aninha-se também o lugar de significação sobre memórias e patrimônio cultural numa relação de sentido com favela, o que particulariza um dizer sobre ela.

Lançando mão de uma paráfrase, temos que não se trata de um museu qualquer nem de qualquer território, mas do primeiro museu de favela do mundo, discurso que produz um efeito de único, singular, inaugural que se sustenta pelo território que recobre. Corrobora este efeito o deslocamento de sentido em relação a acervo de museu uma vez que se enuncia: o acervo são cerca de 20 mil moradores e seus modos de vida, narrativos. Em sua continuidade, este dizer não só circunscreve o objeto museu e o objeto de museu, como os posiciona como parte importante e desconhecida da própria história da Cidade do Rio de Janeiro, dando a ver um apagamento histórico.

Sabemos que a política de gestão da memória, atravessada por relações de força e poder, também é praticada pelos museus na configuração de uma memória de arquivo, isto é, na institucionalização e manutenção de uma região da memória que não deve ser esquecida (ORLANDI, 2013a). É feita para ser lembrada e pode engrendrar-se como "uma gigantesca maquinaria de esquecimento através do ato de aprisionar a memória e fixá-la” (ROBIN, 2016, p. 318). Com isso, podemos dizer que a discursividade acima deixa vestígios de que a favela que constitui o museu de território é importante $e$ 
desconhecida. Ou seja, um discurso que se confronta, no interior da política de gestão da memória, com uma determinada produção de arquivos da qual essa favela não faz parte.

No recorte (R2) abaixo, a formulação território-museu, em sua forma de ligação, é flagrante de uma inversão, pois em vez de museu de território denomina-se territórioтияеu. Com efeito, apesar de sua homologia, põe-se em primeiro plano o território.

R2: O território-museu localiza-se sobre as encostas íngremes do Maciço do Cantagalo, entre os bairros Ipanema, Copacabana e Lagoa, na zona sul da Cidade do Rio de Janeiro, Brasil. Possui 12 hectares de área e um rico acervo de cultura e modos de vida. Tem um patrimônio construído de mais de 5300 imóveis conectados por um impressionante labirinto de becos e escadarias. Seu patrimônio natural reúne Mata Atlântica e vistas panorâmicas notáveis dentre as mais exuberantes paisagens da Cidade Maravilhosa.

Deste recorte, ainda sublinhamos uma ordem de dizer sobre o território-museu que, em seu modo de situá-lo geograficamente e para além dele, o posiciona como um rico acervo de cultura e modos de vida, o significa como patrimônio construído de 5300 imóveis, faz referência ao seu patrimônio natural e o relaciona à cidade maravilhosa. Essa descrição provoca em certa medida uma mexida na rede de filiações aos sentidos, na repetibilidade histórica, ao inscrever uma outra discursividade acerca deste território que não passa pelos já-ditos sobre ele, que não cai "na facilidade do discurso da violência" (ORLANDI, 2004, p. 29).

Politicamente, o Museu de Favela é gestado em um período de implementação de políticas públicas. De Cássia Santos, uma de suas fundadoras, relata que as "primeiras reuniões visando à criação do MUF aconteceram no Canteiro Social destinado aos trabalhadores do Plano de Aceleração do Crescimento (PAC)" (2014, p. 330).

Em termos de conjuntura, é igualmente importante ressaltar a elaboração da Política Nacional de Museus - Memória e Cidadania (PNM) de 2003. Essa política foi elaborada no âmbito do Ministério da Cultura e, certamente, afeta a fundação deste e de outros museus. Isto porque, visando à valorização do patrimônio cultural brasileiro como “dispositivo estratégico de aprimoramento dos processos democráticos" (PNM, 2003, p. 7), a política do PMN produziu um deslocamento importante na maneira de situar o museu na relação com a sociedade, pois o encarrega do papel de gerir a promoção da valorização, preservação e fruição do patrimônio cultural. Essa política aspira à "revitalização de instituições museológicas existentes" e a "criação de novos processos de produção e institucionalização de memórias constitutivas da diversidade social, étnica e cultural do país" como forma de atingir a inclusão social e a cidadania (PNM, 2003, p. 8). 
Vemos esses princípios ressoarem e ganharem um corpo de sentidos na formulação presentificada em outro recorte (R3) do discurso institucional do MUF.

R3: O MUF tem por objetivo preservar a memória da comunidade, promovendo a conexão entre os moradores e a cultura local. Dissolvendo as barreiras entre a favela e o asfalto, o MUF deseja transformar essa comunidade em um Monumento Turístico e Cultural Carioca da História de Formação das Favelas; das origens culturais do Samba; da Cultura do Migrante Nordestino; da Cultura Negra; das Artes Visuais e da Dança.

[...] tem como objetivo promover a conexão e a troca de experiências entre comunidades populares, movimentos sociais e instituições que atuam no campo da memória, patrimônio e cultura.

Todas as ações do MUF têm por temas transversais as memórias da comunidade e a cultura local com intenção educativa, libertária pela expansão da consciência e pela chance de inclusão produtiva, em especial entre adolescentes sujeitos a caminhos de vulnerabilidade social.

A partir dos objetivos preservar a memória da comunidade, promover a conexão entre os moradores e a cultura local, observamos o desencadeamento não só do desejo de dissolver as barreiras entre a favela e o asfalto como também de transformar essa comunidade em um Monumento Turístico e Cultural Carioca da História de Formação das Favelas. Uma forma de relacionar sujeitos com outros sentidos do território, com sua cultura, arte, história; de dar a ver para a sociedade aquilo que é apagado quando a favela é falada por um discurso homogeneizante no qual é marginalizada, significada por estereótipos, segregada.

Nesta direção, ainda como parte da mesma conjuntura, é preciso levar em conta a complexidade do projeto de transformar o morro em Monumento Turístico e Cultural, suas implicações num momento em que visitas às favelas cariocas tornam-se um atrativo turístico, engrenando uma modalidade turística que Freire-Medeiros (2006) chama de tours sociais. A autora salienta que na década de 1990, dada a popularidade internacional dos reality tours, as favelas passam a ser destinos turísticos de visitantes estrangeiros em busca de conhecer o seu "mundo exótico", a imagem vendida globalmente. Reconhecendo esta complexidade, a autora enfatiza que a reflexão sobre o turismo tem ao menos duas facetas, pois pode ser tomado dentro de uma lógica de mercado que converte tudo em produto e consumo, mas, em contraposição, é preciso reconhecê-lo como uma ação social que tem capacidade de "engendrar formas de sociabilidade que produzem efeitos ainda por conhecer" (p. 2).

A constituição do Museu de Favela, a prática de significação que inaugura e os deslocamentos de sentidos que opera não podem ser pensados alheios às injunções 
ideológicas decorrentes destas condições de produção, sobretudo porque elas são constituídas pelo político que divide os sentidos. Além disso, articuladas às formações discursivas, determinam aquilo pode e deve ser dito não só no museu, mas também sobre ele, sobre favela, fora dele, fora da favela.

\section{Um trajeto do processo de biografização}

Dando continuidade à análise, retomamos o processo discursivo de biografização a fim de dar visibilidade para duas de suas formas de funcionar. Como já acentuamos, esse processo é estruturante do Museu de Favela, pois as biografias urbanas são o seu cerne. Um dos indícios disso reside na afirmação de De Cássia Santos (2014) que assinala que a primeira exposição "Um despertar de almas e sonhos" resulta de entrevistas com antigos moradores, o que nos levou a analisar o modo como seu acervo é apresentado.

No site, mais especificamente na aba $\mathrm{ACERVO}^{9}$, este se encontra dividido em: Acervo territorial - Museu vivo - Museu de território; Acervo de memórias, que parece englobar os Circuitos museais; Acervo de exposições e Acervo vivo.

Em relação às discursividades desta aba, observamos um primeiro trajeto do processo de biografização por meio do seguinte recorte (R4):

(R4): "Tenho vários nomes: Morro, Maciço do Cantagalo, Pavão-PavãozinhoCantagalo, por um tempo virei sigla PPG, porém na paz volto a ser Cantagalo, Pavão e Pavãozinho. Classificam-me também de AEIS - Área Especial de Interesse Social, coisa de lei da Cidade do Rio de Janeiro, desde 2003, dizem que é para assegurar o lugar desse povo que me ocupou, protegido da predação de um tal de mercado imobiliário que, no rastro da urbanização, da pacificação, da regularização, aproveita da valorização compra e expulsa quem lutou e mereceu o progresso."

"De uns tempos pra cá sou MUF também... como um sopro que desperta"...

"Trecho do livro Circuito das Casas-Tela"

Como se o território se apresentasse: esse é o efeito produzido à medida que vemos a biografização ganhar, metaforicamente, corpo na "voz" do território. Ele é personificado e fala de si mesmo, em primeira pessoa: Tenhos vários nomes. Evocam-se, neste processo, diferentes regiões da memória discursiva ao se lançar algumas nomeações, definições administrativas, referência ao povo que o ocupou em face de uma discursividade que conjuga dizeres sobre a ocupação, a predação imobiliária, a urbanização, a pacificação, a explusão. Discursos que constituem a história das favelas,

\footnotetext{
${ }^{9}$ Na página há uma observação de que o site está em construção.
} 
mas que aqui é contada "como se fosse" pelo próprio território vivo. Por fim, numa junção de vozes, que une território e museu, "ele diz que" De uns tempos pra cá sou MUF também ... como um sopro que desperta.

A exposição "Um despertar de almas e sonhos" aparece listada no Acervo de exposições junto de outras duas exposições "Velhos Ilustres" e "Mulheres Guerreiras". Contudo, é na aba ATIVIDADES, dividida em Oficinas, Projetos Culturais e Exposições, que encontramos textos expográficos nos quais se textualiza a descrição das duas últimas exposições.

No texto expográfico de "Mulheres Guerreiras" é dito que ela é uma exposição itinerante e também uma extensão do prêmio Mulheres Guerreiras, lançado em 2011 na V Primavera de Museus do Instituto Brasileiro de Museus (IBRAM), que teve como tema Mulheres, Museus e Memórias. Por meio de entrevistas com doze mulheres, moradoras do Cantagalo, foram selecionadas as histórias que mais representam a memória coletiva desse complexo de favelas, conforme é descrito no recorte abaixo (R5):

(R5): A escolha e seleção das mulheres foram realizadas pelo Colegiado do Museu de Favela, integrado por moradores das três favelas, indicando as mulheres a serem entrevistadas e selecionando as histórias que mais representam a memória coletiva desse complexo de favelas. Convidamos a todos a conhecer as emocionantes vidas das guardiãs das memórias desse grande território museal.

Na relação entre as histórias que mais representam e a memória coletiva desse complexo de favelas, destaca-se o lugar significante que é atribuído às vidas dessas mulheres, que são significadas como guardiãs das memórias desse grande território museal. Neste discurso, sujeito e espaço urbano estão articulados e sustentando a relação território-museu-memória. São essas histórias que são impedidas de significar muitas vezes e de ocuparem também um lugar na memória de arquivo da cidade.

No site, não há registros visuais dessa exposição, mas encontramos uma foto $\left(\right.$ R6) ${ }^{10}$ de uma das incursões da exposição. Por ela, é possível observar como a exposição é montada e de que maneira um processo discursivo de biografização é desencadeado, ganha corpo simbólico.

\footnotetext{
${ }^{10}$ Série Mulheres Guerreiras MUF. Foto disponível em: https://rioonwatch.org.br/?p=17296. Acesso em 17 de junho de 2020.
} 


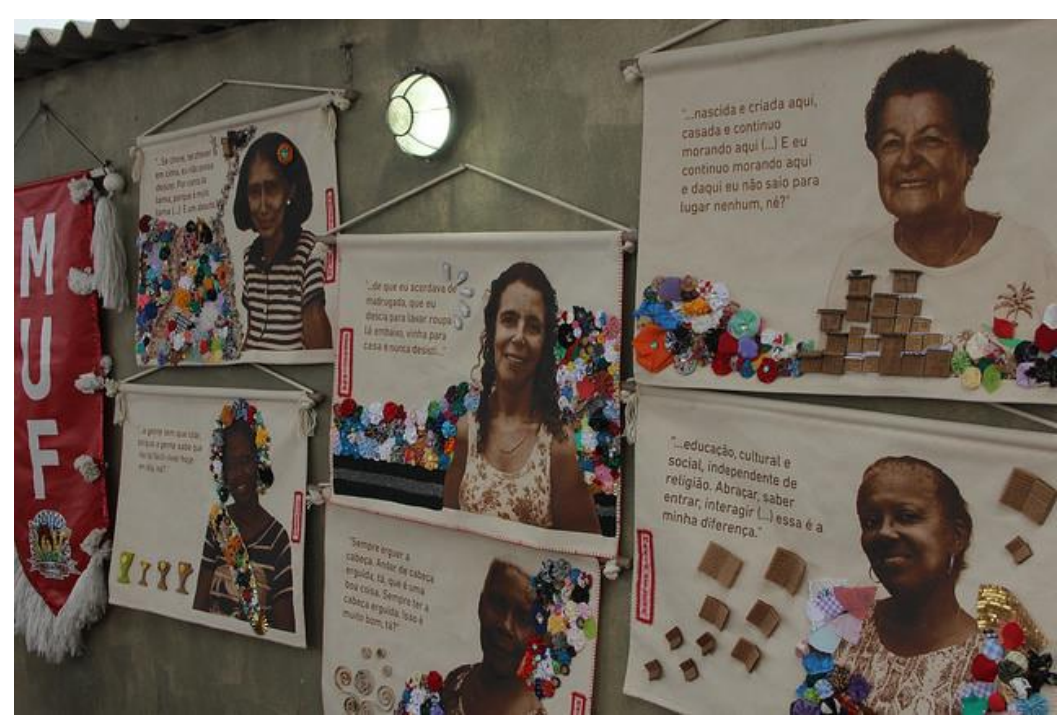

R6: Foto da exposição itinerante "Mulheres Guerreiras"

Modos de ser e habitar a cidade. Mulheres Guerreiras contam e de certa forma são contadas nesta exposição. Elas expõem a vida dando corpo, gênero, sentidos à favela e a sua história. São mulheres com rostos e histórias que vivificam o território-museu.

Cada biografia é emoldurada em uma tela. É adornada pela arte, pela cor, pela delicadeza do artesanato. Trechos de entrevistas estão grafados ao lado de imagem de cada mulher em uma mesma tela. Torna-se obra de arte.

O processo discursivo de biografização assim ressignifica o curso histórico da musealização, pois mexe em todas as suas etapas, principalmente, no estatuto de obra, peça de museu ao torná-la um espaço vital de existência. Ademais, é por este processo não linear, nem homogêneo, que outras discursividades podem se movimentar na sociedade e se inscrever no discurso citadino, na história.

De parede em parede, essas biografias urbanas são feitas para circular. Como efeito, em sua circulação, outros discursos sobre sujeito e espaço urbano em con(vivência) no afeto que abre caminho para o real irromper perturbando a ordem das coisas-a-saber.

\section{Questões para terminar}

Longe de esgotar esta reflexão, encerramos este artigo apontando para duas questões prementes em relação ao Museu de Favela.

A primeira consiste em aventar a possibilidade do MUF, enquanto museu de território, operar uma apropriação de meios de existência, na medida em que conduz a produção de arquivos da/sobre a vida da/na favela que não devem ser esquecidos. Pelo o 
que observamos, há um movimento, nesta direção, de alçar um lugar na história para além dos discursos homogeinizantes tais como os de violência já saturadamente inscritos na memória discursiva.

E a segunda questão recai sobre a constituição do sujeito, em especial, sobre a sua individuação. De acordo com Orlandi (2001b), a constituição do sujeito passa por dois momentos principais: o da interpelação do indivíduo pela ideologia e o da individuação da forma sujeito pelo Estado e suas instituições. A autora explica que é na individuação do sujeito que pesa o modo como a instituição, neste caso o museu, e seus discursos, o produzem como tal, pois aí se estabelecem as condições para seu processo de identificação com um ou outro sentido, esta ou aquela posição discursiva na sociedade e na história (ORLANDI, 2001b). Sendo assim, cabe-nos acentuar a possibilidade de haver a produção de diferentes efeitos na identificação tanto dos sujeitos do Museu de Favela, aqueles que estão no cerne de sua estrutura, na relação com sua própria história, quanto dos sujeitos visitantes do museu, aqueles que estabelecem por uma outra entrada uma relação com as biografias urbanas. É preciso levar em conta, por conseguinte, que as relações sociais são dissimétricas em face da identificação do sujeito e da produção dos efeitos de sentido uma vez que os processos ideológicos são marcados pela contradição e pela assimetria.

\section{Referências bibliográficas}

BRASIL. Ministério da Cultura. Bases para a Política Nacional de Museus: Memória e Cidadania. Brasília: Minc, 2003.

BRULON, Bruno. A invenção do ecomuseu: O caso do Écomusée du Creusot Montceaules-Mines e a prática da museologia experimental. Mana, v. 21, n. 2, p. 267-295, 2015.

CHAGAS, Mário Souza. Museus, memórias e movimentos sociais. Cadernos de sociomuseologia, n. 41, p. 5-16, 2011.

COSTA, Greciely Cristina. Discurso, Cidade e História: metonimização entre favela e favelado e seus efeitos. In: ANDRADE, Alexandre Carvalho de; ANDRADE, Ana Eugênia Nunes de (Orgs). Cidades em movimento. Jundiaí: Paco Editorial, 2013.

DE CÁSSIA SANTOS, Rita. Becos e vielas do Museu de Favela. Revista Cadernos do Ceom, v. 27, n. 41, p. 329-336, 2014.

DELORY-MOMBERGER, C. Sens et narrativité dans la société biographique. Le sujet dans la Cité, n³, p. 167-181, 2012.

FREIRE-MEDEIROS, Bianca. A construção da favela carioca como destino turístico. Rio de Janeiro: CPDOC, 2006. Disponível em: http://bibliotecadigital.fgv.br/dspace;/bitstream/handle/10438/4138/TurismoFavelaCario ca.pdf? sequence $=1 \&$ is Allowed $=y$ 
PFEIFFER, Claudia Regina Castellanos. Língua em museu: institucionalização de um nós no recobrimento de um resto histórico. Letras, n. 46, p. 225-244, 2013.

ORLANDI, Eni Puccinelli. Tralhas e troços: o flagrante urbano. In: ORLANDI, Eni Puccinelli (Org.). Cidade Atravessada: os sentidos públicos no espaço urbano. Campinas, SP: Pontes, 2001a.

ORLANDI, Eni Puccinelli. Discurso e texto: formulação e circulação dos sentidos. Campinas, SP: Pontes, 2001b.

ORLANDI, Eni Puccinelli. Cidade dos Sentidos. Campinas, São Paulo: Pontes, 2004.

ORLANDI, Eni Puccinelli. Discursos e museus: da memória e do esquecimento. Signo y seña, n. 24, p. 11-20, $2013 a$.

ORLANDI, Eni Puccinelli. A palavra dança e o mundo roda: Polícia!! In: GUIMARÃES, Eduardo (Org.), Cidade, Linguagem e Tecnologia: 20 anos de história. Campinas, SP: LABEURB, 2013b.

ORLANDI, Eni Puccinelli. Era uma vez corpos e lendas: versões, transformações, memória. In: Eu, tu, ele: discurso e real da história. Campinas, SP: Pontes, 2017.

PÊCHEUX, Michel. Delimitações, inversões, deslocamentos. Cadernos de estudos linguísticos, Campinas, v. 19, pp.7-24, jul./dez, 1990.

PÊCHEUX, Michel. O discurso: estrutura ou acontecimento. Trad. Eni Puccinelli Orlandi. Campinas, SP: Pontes, 1997.

PÊCHEUX, Michel. Leitura e Memória: projeto de pesquisa. In: ORLANDI, Eni Puccinelli (Org.), Análise de Discurso: Michel Pêcheux - textos escolhidos por Eni Puccinelli Orlandi. Campinas, SP: Pontes, 2011.

PÊCHEUX, Michel. Análise Automática do Discurso. Trad. Eni Puccinelli Orlandi e Greciely Costa. Campinas, SP: Pontes, 2019 [1969].

ROBIN, Régine. A memória saturada. Trad. Cristiane Dias e Greciely Costa. Campinas: Editora da Unicamp, 2016.

SCHEINER, Tereza Cristina. Repensando o Museu Integral: do conceito às práticas. Boletim do Museu Paraense Emílio Goeldi. Ciências Humanas, v. 7, n. 1, p. 15-30, 2012.

SCHMIDT, Benito Bisso. Biografia e regimes de historicidade. Métis: história \& cultura, v. 2, n. 3, 2003.

VARINE, Hugues de. Un témoignage sur les écomusées en Europe et dans le monde depuis vingt ans. Texto apresentado no Encontro sobre museus em Biella, Itália, p. 1-5, 2003. Disponível em: http://www.ecomusei.eu/mondilocali/wpcontent/uploads/2011/03/2003-de-Varine.pdf. Acesso em 17 de junho de 2020. 


\section{Para citar essa obra:}

COSTA, Greciely Cristina. Museu de Favela e biografias urbanas. In: RUA [online]. Volume 26, número 2 - p. 573 - 591 - e-ISSN 2179-9911 - Novembro/2020. Consultada no Portal Labeurb - Revista do Laboratório de Estudos Urbanos do Núcleo de Desenvolvimento da Criatividade. http://www.labeurb.unicamp.br/rua/

Capa: Detalhe do quadro Bal du moulin de la Galette. Auguste Renoir Disponível em: http://www.musee-orsay.fr/en/collections/works-infocus/search/commentaire_id/dance-atle-moulin-de-la-galette

\section{Laboratório de Estudos Urbanos - LABEURB}

Núcleo de Desenvolvimento da Criatividade - NUDECRI

Universidade Estadual de Campinas - UNICAMP

http://www.labeurb.unicamp.br/

\section{Endereço:}

LABEURB - LABORATÓRIO DE ESTUDOS URBANOS

UNICAMP/COCEN / NUDECRI

CAIXA POSTAL 6166

Campinas/SP - Brasil

CEP 13083-892

Fone/ Fax: (19) 3521-7900

Contato: http://www.labeurb.unicamp.br/contato 